\title{
Heat Transfer from Superheated Vapors to a Horizontal Tube
}

GAREN BALEKJIAN and DONALD L. KATZ

University of Michigan, Ann Arbor, Michigan

Experimental data are reported for condensing Freon-114 (tetrafluorodichloroethane) and steam at several pressures. The condition of the vapors ranged from saturation to $180^{\circ} \mathrm{F}$. of superheat. The condensing tube containing embedded thermocouples was $3 / 4$ in. in diameter and $3 \mathrm{ft}$. long. Visual observation showed that steam condensed by dropwise condensation in part. Increase of superheat in the vapor at constant pressure caused a lowering of the tube-wall temperature, which was indicative of a lowering of the surface temperature of the condensate. The lowering of the condensate-surface temperature below the saturation temperature was computed from the experimental tube-wall temperatures, the heat flux, and Nusselt's equation for the condensate-film resistance. The lowering of the condensate-surface temperature is correlated with degree of superheat. An interfacial coefficient of heat transfer between the superheated vapor and the condensate surface is reported based on the computed surface temperatures. Schrage's analysis and equations for relating mass and heat transfer with conditions at an interface were simplified and used to correlate the experimental condensing load with the degree of superheat.

The condensation of superheated vapors is frequently encountered in industry, for instance in vapor leaving compressors. A superheated vapor in contact with a surface at temperatures below the dew point of the vapor will form a condensate film on the cold surface. The heat extracted from the vapor passes through the liquid film much as in the condensation of saturated vapors. The difference in the condensation of superheated vapors from the process for saturated vapors lies in the removal of the superheat from the vapor at an extremely short distance from the condensate surface and in the effect that this process has on the temperature of the liquid at the vapor-liquid interface. The proper design of a superheated vapor condenser requires the formulation of a theory whereby the behavior of superheated vapors may be predicted for a wide range of pressures and superheats in order to anticipate the peculiar condenser condition when the tube surface is no longer wetted with a liquid film.

The classical work of Nusselt (21) presents theoretical equations for the condensation of vapors on different surfaces. The derivation of these equations and a detailed discussion of the experimental data on this subject is available in several references $(8,9,11$, $13,14,17,18$, and 20 ). The effect of condensate-film turbulence on the condensate-film coefficient is observed by Kirkbride (16). Other factors such as vapor velocity and its effect on the turbulence of the condensate film and literature related to them are reviewed in reference 29.

The condensation of superheated vapors

Garen Balekjian is at present with C. F. Braun and Company, Alhambra, California. is discussed in the original work of Nusselt (21). The integrated equations for the condensate-film thickness on a vertical plate and the corresponding condensing load are presented in references 14 and 20. Using an approximation of the analytical results, Stender (26) and Merkel (19) predict an increase of up to $37 \%$ in the heat flux due to superheat (20). Katz et al. (15) report the results of their studies for superheated Freon-12 condensing on the outside of horizontal plain and finned tubes. No effect of superheat as compared with saturated vapors is observed for the range of pressure of 103 to $172 \mathrm{lb} . / \mathrm{sq}$. in: abs. and the maximum superheat of $122.5^{\circ} \mathrm{F}$. Nusselt's derivation of an equation applied to superheated vapors gives an equation similar to that for saturated vapors where the factor $(-\Delta H)$ represents the total heat removed in condensing the superheated vapors. This equation predicts a small increase in heat flux due to superheat. Conventional design of superheated vapor condensers is based on the condensate film coefficient predicted by this method. 
Condensation of superheated vapors involves the transfer of mass and energy across the vapor-liquid film. The statistical behavior of molecules predicted from the kinetic theory of gases is useful in relating the temperature and pressure conditions of the system with the rate of mass and energy transfer. The work of Schrage (24) presents the basic equations applicable to condensation and vaporization phenomena. The following relationship is derived for the rate of interphase transfer and the prevailing temperature and pressure conditions:

$m_{s}=h_{f} \sqrt{\frac{g_{c} \bar{M}}{2 \pi R T_{s}}}\left[P_{*}^{*}-P_{o}\left(\frac{T_{s}}{T_{s}}\right)^{1 / 2} \Gamma\right]$

The variable $\Gamma$ in Equation (1) is a correction factor involving the error integral and is evaluated as a function of

$$
\phi_{o}=\sqrt{\frac{g_{c} M}{2 R T_{g}}} u_{g}
$$

Subseripts $s$ and $g$ refer to conditions at the vapor-liquid interface and the vapor region respectively. The condensation coefficient $h_{f}$, defined as the ratio of molecules condensed to the total number of molecules striking the surface, is assumed to be constant and independent of the molecular vector velocity. It is a function of the state of the surface and the kind of molecules involved. The derivation of Equation (1) does not assume equilibrium conditions at the interface. The maximum rate of evaporation or condensation is used in the derivation of Equation (1) and is defined as

$$
m_{e}=h_{f} P_{\mathrm{s}}^{*} \sqrt{\frac{g_{c} \bar{M}}{2 \pi R T_{s}}}
$$

The use of Equation (1) to predict the deviation from equilibrium for actual cases is made difficult by the functional interdependence of $m_{s}, m_{e}, h_{f}, \Gamma$, and $\phi_{o}$. Schrage defines $\phi_{g}$ by the following equation:

$$
\phi_{g}=\frac{1}{2 \pi^{1 / 2}} \frac{m_{a}}{m_{e}}\left(\frac{P_{s}^{*}}{P_{g}}\right)\left(\frac{T_{g}}{T_{s}}\right)^{1 / 2}
$$

A modified form of Equation (1) is used extensively in the literature concerning interphase transfer phenomena:

$$
m_{\mathrm{s}}=h_{f}\left(P_{\mathrm{s}}^{*}-P_{\mathrm{g}}\right) \sqrt{\frac{g_{c} M}{2 \pi R T_{s}}}
$$

Equation (4) involves the assumption of interfacial equilibrium

$$
\Gamma=1.0,\left(\frac{T_{\mathrm{s}}}{T_{\mathrm{o}}}\right)=1.0
$$

Equations (2) and (4) are used by Alty and coworkers ( 1 to 5 ) for the experimental evaluation of the condensation

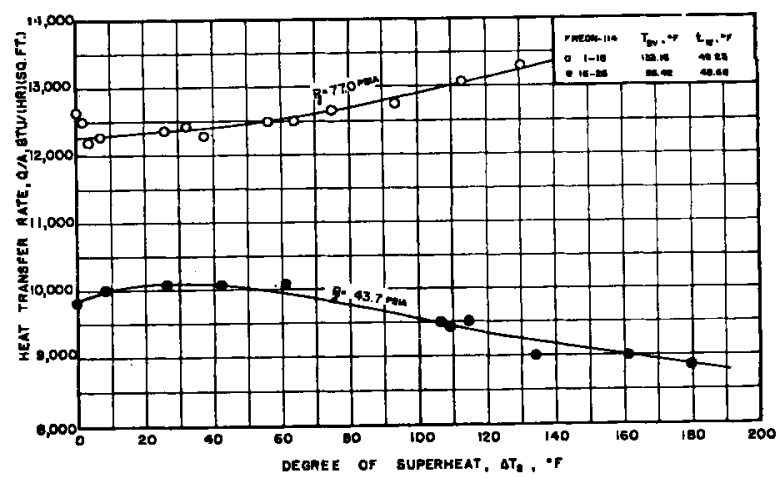

Fig. 2. Effect of superheat on heat flux for condensation of Freon-114.

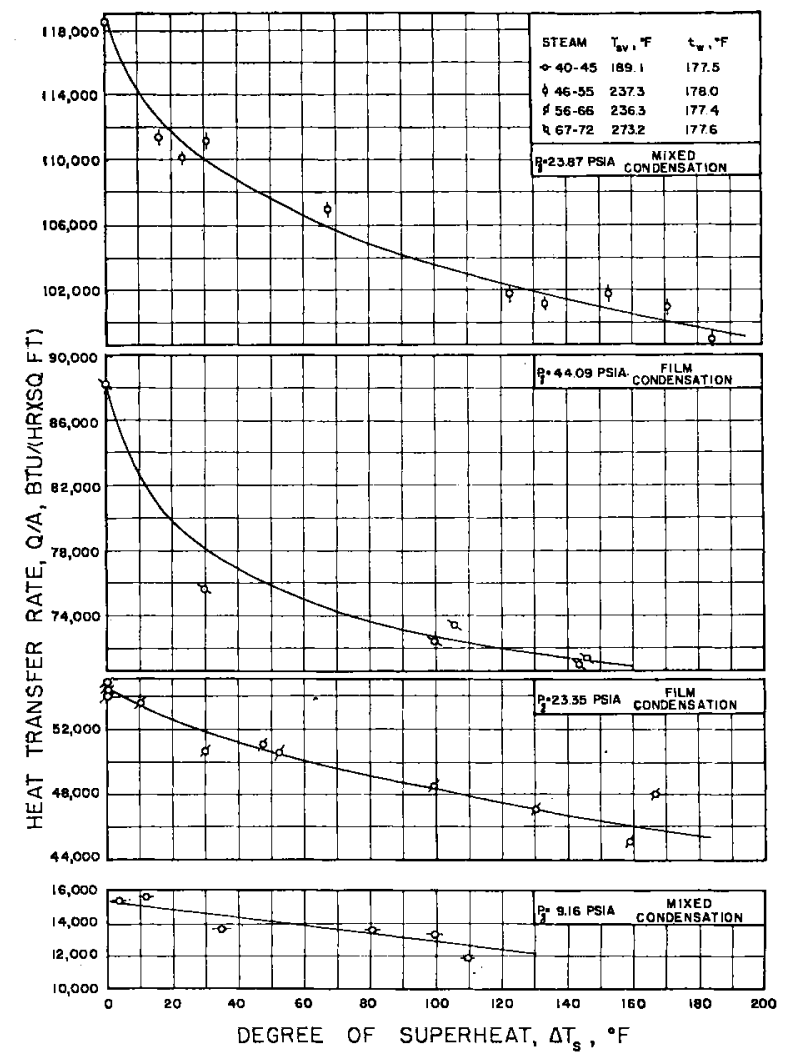

Fig. 3. Effect of superheat on heat flux for condensation of steam. 
coefficient $h_{f}$ for water, carbon tetrachloride, and several other liquids and solids. It is concluded that the condensation coefficient of polar compounds is relatively small, whereas that of nonpolar compounds is very close to unity. Prüger (2ं) has determined the condensation coefficient of water and carbon tetrachloride at atmospheric pressure. The values of $h_{f}$ of 0.04 and unity for water and carbon tetrachloride respectively agree with those reported by Alty. A recent study (12) on the rate of condensation of water vapor under vacuum presents a correlation based on Equation (2).

The concept of the lowering of the condensate-surface temperature below that of the saturated vapor during the condensation of superheated steam is reported by Jakob (19), and a theoretical attempt to prove lowering of the condensate-surface temperature below the saturation temperature is made by Bosnjakovic (7).

Using the approximate Equation (4) along with the Clapeyron equation Silver (25) has defined an interfacial film coefficient for the evaluation of condensate subcooling during the condensation of saturated steam at low pressures. The interfacial film coefficient $h_{i}$ based on $\left(T_{s v}-T_{s}\right)$ and $h_{f}=0.036(2)$ is defined as

$h_{i}=\cdot 778 h_{f} \sqrt{\frac{g_{c} M}{2 \pi R T_{\mathrm{g}}}} \frac{(-\Delta H)^{2} \rho_{L}}{T}$

Equation (5) is used by Cornell (10) in a method recommended for the evaluation of the condensate surface temperature $\left(T_{s}\right)$, the interfacial film coefficient $\left(h_{i}\right)$, and the temperature drop across the interfacial film for the condensation of superheated steam. It is assumed that the vapor at the interface is at the saturation temperature and that the temperature drop through the interfacial film is of the same order as that for a saturated vapor.

\section{EXPERIMENTAL APPARATUS}

The experimental apparatus consists of a closed system for generating vapor, superheating it, condensing the superheated vapor, and returning condensate to the vapor generator. Figure 1 presents the flow diagram describing the experimental apparatus.

The essential feature of the apparatus is the horizontal condenser tube $3 / 4$ in. in outside diameter and $3 \mathrm{ft}$. long, housed in a 6-in. shell. The limited surface and large shell reduce the effects of vapor velocity and condensate splashing on shell-side heat transfer. Four thermocouples made from 30-gauge copper-constantan wires are installed circumferentially in the tube wall to measure the temperature. Two of these thermocouples are located at the wateroutlet end of the experimental tube, one at the top and the other $90 \mathrm{deg}$. from the

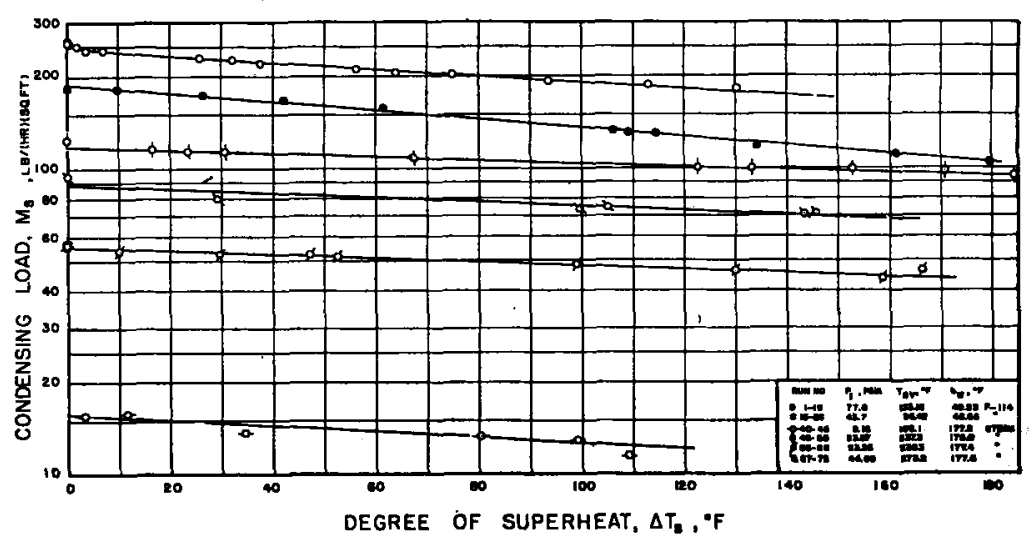

Fig. 4. Effect of superheat on condensing load for condensation of Freon-114 and ${ }_{2}^{7}$ steam.

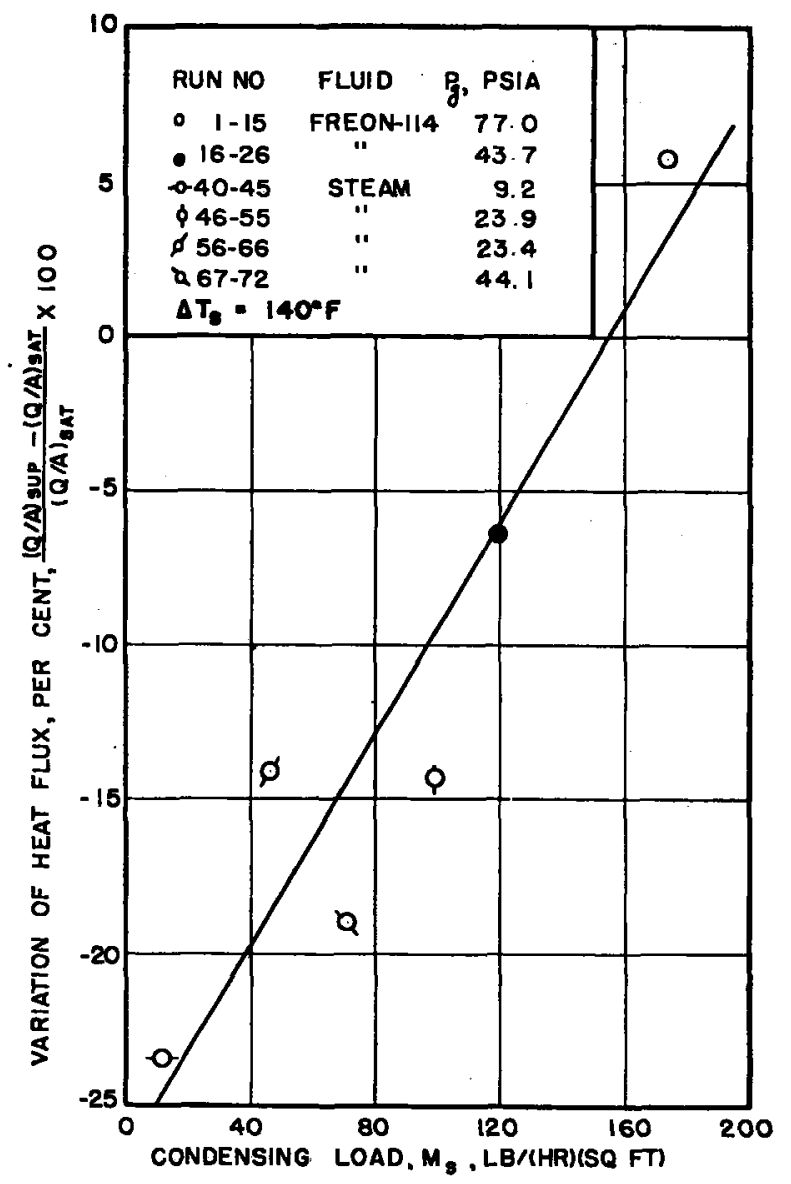

Fig. 5. Correlation of the effect of superheat on the heat flux with the condensing load. 


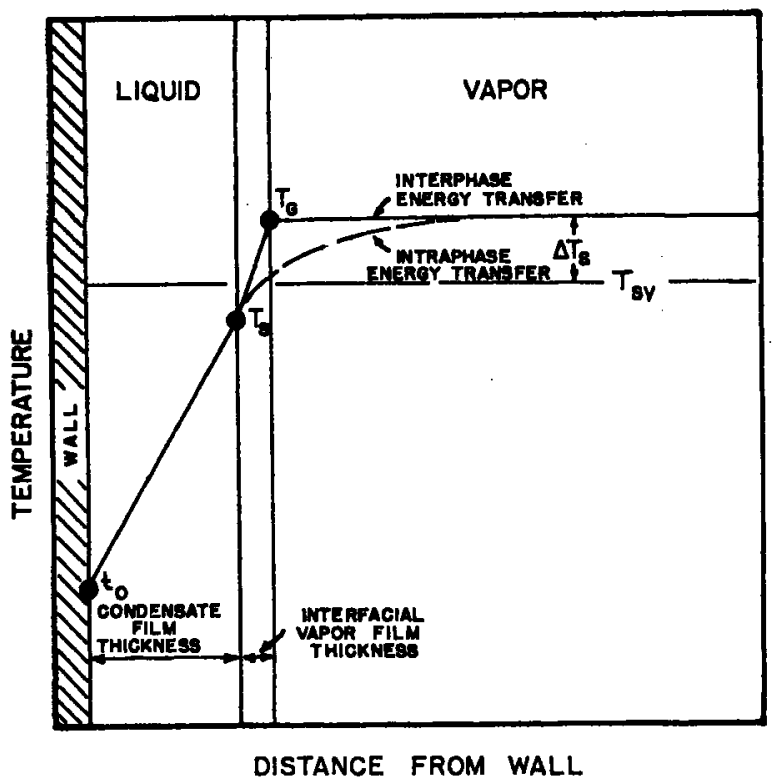

Fig. 6. Temperature profile for a condensing superheated vapor.

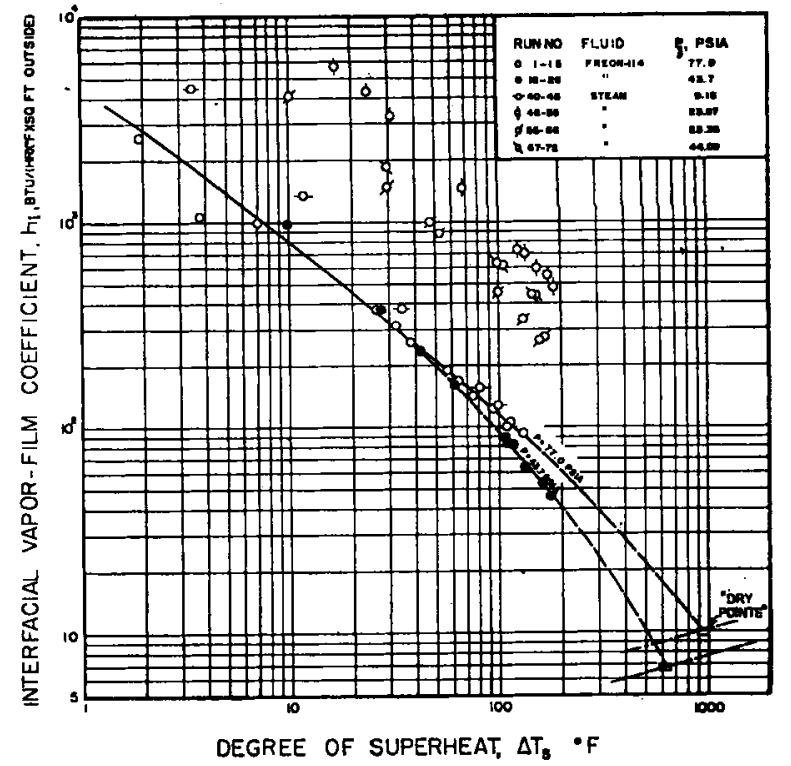

Fig. 7. Effect of superheat on interphase vapor-film coefficient $h_{i}$ for condensation of Freon-114 and steam. top position. The third and fourth thermocouples are at the middle and at the water-inlet end of the tube respectively, both at the top position. The end thermocouples are spaced $3 \frac{1}{16}$ in. from the inner surface of the condenser headers, and the thermocouple at the center of the tube is spaced $15 \frac{7}{32}$ in. from those at the ends. Water at a controlled temperature is circulated through the tube to extract the heat from the condensing vapor. The heat transfer rate is determined by the temperature rise of the water measured with mercury-in-glass thermometers and by the water flow rate indicated by a calibrated rotameter. Two iron-constantan thermocouples in the vapor space of the condenser indicate the temperature of the vapor. The degree of superheat in the vapor is automatically controlled by an electric superheater. The superheater and condenser are lagged heavily with insulation to reduce variation of the vapor temperature in the condenser.

Water and Freon-114 (tetrafluorodichloroethane) are selected for this study as two fluids with widely different properties. Freon-114 is chosen as the organic fluid because it has a suitable vapor pressure and generally gives stable film condensation. At the time steam was selected, it was expected that it would be made to condense by film; however, for most of the data on steam the condensation was a mixture of drop and film condensation. At a given condenser pressure the auxiliary equipment is arranged to provide hot water at a constant temperature and flow rate. The absence of noncondensables is indicated by the constant heat flux at steady state conditions, after the bleeding off of a portion of the condenser vapor.

The experimental data consist of the following measurements: condenser temperatures, condenser tube-wall temperatures, water flow rate, inlet and outlet water temperatures, condenser pressure, barometric pressure, and room temperature.

\section{EXPERIMENTAL DATA}

Condensation of Freon-114 is studied at two pressures of 77.0 and $43.7 \mathrm{lb}$./sq. in. abs. and different vapor superheats ranging from $0^{\circ}$ to $180^{\circ} \mathrm{F}$. Four sets of comparable data are obtained for steam at pressures of 9.2 , $23.4,23.9$, and $44.1 \mathrm{lb}$./sq. in. abs. and maximum superheats varying from $109^{\circ}$ to $184^{\circ} \mathrm{F}$. Runs made at 23.4 and $44.1 \mathrm{lb}$. $/ \mathrm{sq}$. in. abs. constitute data with primarily film condensation of steam.

The condensing-water flow rate varies for the different condenser pressures, the range being from 7 to $18 \mathrm{ft}$./sec. Watertemperature rise for the test runs varies from $1.9^{\circ}$ to $11.6^{\circ} \mathrm{F}$. Under these conditions the portion of the thermal resistance due to condensing water is $50 \%$ or less. The tubewall thermocouples indicate a maximum temperature variation of $6.5^{\circ} \mathrm{F}$. along the tube. A circumferential temperature variation is observed from the two thermocouples at the water-outlet end of the tube. The thermocouple at the top position indicates wall temperatures which are $0.5^{\circ}$ to $2^{\circ} \mathrm{F}$. higher than those of the thermocouple located 90 deg. from the top. The maximum variation of the vapor temperature from the two condenser thermocouples is $1^{\circ}$ to $2^{\circ} \mathrm{F}$, at the highest superheats investigated. Experimental data and calculated results are available in reference 6 .

The degree of superheat is defined as the difference between the temperature of the superheated vapor and the saturation temperature corresponding to the condenser pressure. The experimental heat fluxes are presented in Figure 2 for Freon-114 and in Figure 3 for steam. The general trend is a gradual decrease in the heat flux due to superheat. The effect of superheat on the heat flux varies for the various pressures. It is interesting to observe the trend indicated for the effect of superheat on the condensing load in order to interpret the over-all performance of superheated vapors. The calculated condensing loads are presented in Figure 4 on a semilogarithmic plot of the condensing load vs. the degree of superheat. In all cases the condensing load decreases gradually with the superheat. A comparison of Figures 2 and 3 with Figure 4 indicates that at the lowest condensing loads represented by the stenm data at $9.2 \mathrm{lb} . / \mathrm{sq}$. in. abs. the reduction in heat flux at $140^{\circ} \mathrm{F}$. superheat compared with the heat flux at saturation is a maximum of $23.4 \%$. For intermediate condensing loads this reduction is 14.1 to $19.0 \%$. For the higher condensing loads represented by the Freon-114 data at $43.7 \mathrm{lb}$./sq. in. abs. the reduction in the heat transfer rate is a minimum of $6.4 \%$ for the same degree of superheat. At the highest condensing loads with Freon-114 at $77.0 \mathrm{lb}$./sq. in. abs. the trend in the heat transfer rate is reversed and there is an increase of $5.8 \%$ in the heat flux.

These results indicate that the trend obtained for the effect of superheat on the heat-flux curve depends on the condensing load (Figure 5). This is due to the fact that an uncertain amount of desuperheating of the vapor occurs in the condenser because of the intimate contact of the subcooled condensate with the vapor surrounding it. The discrepancy shown in Figure 5 by some steam results is due primarily to the difference in the tube-side water-flow rates and the type of condensation obtained.

\section{Interfacial Film Coofficients}

The difficult measurement of the vapor and liquid temperatures at the interface as shown in Figure 6 is not feasible in this investigation. For the case of stable film condensation the condensate film coefficient is calculated for the saturated vapor from the Nusselt equation, the measured tubesurface temperature, and the condensing load. For Freon-114 the calculated condensate-film coefficient is $4.1 \%$ higher at 77.0 lb. $/ \mathrm{sq}$. in. abs. and $17.5 \%$ lower at 43.7 lb./sq. in. abs. than the corresponding experimental value. The fair agreement between the two results indicates the possibility of calculating the condensate-surface 
temperature for the results with superheated Freon-114 and steam. Assuming the available temperature drop between the superheated vapor and the condensate surface to occur at the vapor-liquid interface makes possible the calculation of the corresponding interfacial-film coefficient. The validity of this assumption is shown by the extent to which experimental results agree with the theory. The interfacialtemperature difference is calculated as

$$
\Delta t_{i}=\left(T_{g}-T_{s}\right)
$$

The interfacial film. coefficient is defined by the following equation:

$$
h_{i}=\frac{Q}{A \Delta t_{i}}
$$

Actual thickness of the interfacial film (Figure 6) is very small, of the order of a molecular mean free path. Since the exact location and area of the interface are unknown, a good approximation for $A$ in Equation (7) is the outside-tube-surface area.

Figure 7 presents the relationship between the calculated interfacial-film coefficients and the degree of superheat for Freon-114 and steam results. As the degree of superheat is increased, the condensing load decreases, the condensate-film coefficient increases, and the interfacial-film coefficient decreases. The interfacial-film coefficient is infinite for a saturated vapor. $\mathrm{Up}$ to a superheat of about $30^{\circ} \mathrm{F}$. the effect of pressure on the interfacial-film coefficient of Freon-114 seems to be relatively small (Figure 7). The more pronounced spacing of the steam results is to be accounted for partly by the variable extent of the condensation by drops observed with steam.

Figure 7 is useful in predicting conditions of superheat in the region, close to the "dry point." This region characterizes the superheated vapor temperatures at which the tube surface is dry and the outside film coefficient is represented by the interfacial film coefficient. In the region close to the "dry point" the outer-tube-surface temperature approaches the tube-side fluid temperature. It is reasonable to assume that under these conditions the interfacial-film coefficient is of the order of the combined natural convection and radiation coefficients. Dashed lines representing these calculated coefficients are shown in Figure 7.

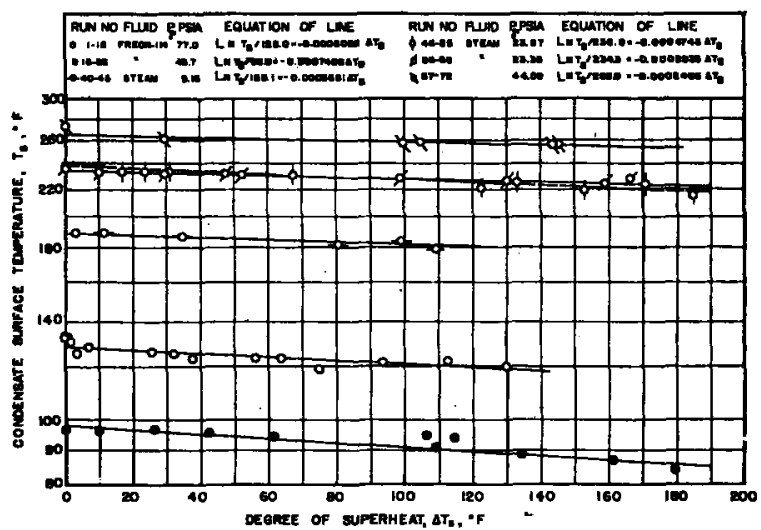

Fig. 8. Correlation of calculated condensate surface temperature with superheat for condensation of Freon-114 and steam.
Intersection of these lines with the extrapolated interfacial-film coefficients gives the calculated dry points. For Freon-114 at 43.7 and $77.0 \mathrm{lb}$./sq. in. abs. the dry point corresponds to a superheat of $625^{\circ}$ and $925^{\circ} \mathrm{F}$. respectively.

\section{CORRELATION OF CONDENSING LOAD}

The theory on interphase mass and energy transfer is used for the correlation of experimental and calculated results. The condensate-surface temperatiure calculated as described in the preceding section is presented as a function of the degree of superheat in Figure 8. The semilogarithmic plot indicates a straightline relationship. Lines are drawn to represent the best trend indicated by the calculated points. The equations of these lines given in Figure 8 show the mean saturation temperature for all the runs in a given set corresponding to the mean condenser pressure. Saturation and condensate-surface temperatures used for the correlation of experimental heat transfer rates and condensing loads are obtained from the lines shown in Figure 8.

Direct application of Equation (1) for the correlation of results is complicated because of the correction factor $\mathrm{r}$, as indicated earlier. This relationship is simplified by expressing $\Gamma$ as a simple function of $\phi_{0}$ defined by Equation (3). Values of $(\Gamma-1)$ are presented graphically for condensation $\left(\phi_{g}<0\right)$ and evaporation $\left(\phi_{g}>0\right)$ in reference 24 for the range $1.0 \geq\left|\phi_{g}\right| \geq 0.001$. The major portion of this graph corresponding to the range of $0.1 \geq\left|\phi_{s}\right| \geq 0.001$ is represented satisfactorily by a straight line with a slope of unity. The following equation approximates the calculated values of $\boldsymbol{\Gamma}$ for condensation with a maximum deviation of $\pm 4 \%$ :

$$
\begin{aligned}
& \Gamma=1+1.85\left|\phi_{g}\right| \\
& \quad \text { for } 0.1 \geq\left|\phi_{g}\right| \geq 0.001
\end{aligned}
$$

On substitution for the absolute rate of evaporation $\left(m_{\varepsilon}\right)$ from Equation (2) into Equation (3), $\phi_{g}$ is expressed as

$$
\phi_{g}=\frac{m_{s}}{2 \pi^{1 / 2} h_{f} P_{g}} \sqrt{\frac{2 \pi R T_{s}}{g_{c} M}}\left(\frac{T_{g}}{T_{s}}\right)^{1 / 2}
$$

Substituting for $\Gamma$ in Equation (1) the linear function given by Equation (8) and solving for $\phi_{a}$ yields

$$
\begin{aligned}
\phi_{\sigma} & =\frac{1}{1.85}\left(\frac{P_{s}^{*}}{P_{g}}\right)\left(\frac{T_{g}}{T_{\mathrm{s}}}\right)^{1 / 2} \\
- & \frac{m_{\mathrm{s}}}{1.85 h_{f} P_{g}}\left(\frac{T_{g}}{T_{\mathrm{s}}}\right)^{1 / 2} \sqrt{\frac{2 \pi R T_{s}}{g_{\mathrm{g}} M}}-\frac{1}{1.85}
\end{aligned}
$$

If Equations (9) and (10) are combined to eliminate $\phi_{g}$, the following equation is derived for the condensation coefficient $h_{f}$ :

$$
h_{f}=\frac{1.52 m_{\mathrm{a}} \sqrt{\frac{2 \pi R T_{\mathrm{s}}}{g_{c} M}}}{\left[P_{\mathrm{s}}^{*}-P_{\mathrm{g}}\left(\frac{T_{\mathrm{g}}}{T_{\mathrm{g}}}\right)^{1 / 2}\right]}
$$

Equation (11) is equivalent to Equation (1), discussed earlier, with the correction factor $\Gamma$ replaced by its equivalent constant factor of 1.52 . A relationship similar to Equation (11) is presented by Bosnjakovic (7) without the constant factor. On substitution for $\sqrt{2 \pi R / g_{0}}$ Equation (11) is simplified to

$$
h_{f}=\frac{m_{\mathrm{s}} \sqrt{\frac{T_{\mathrm{s}}}{M}}}{19,630\left[P_{*}^{*}-P_{v}\left(\frac{T_{s}}{T_{g}}\right)^{1 / 2}\right]}
$$

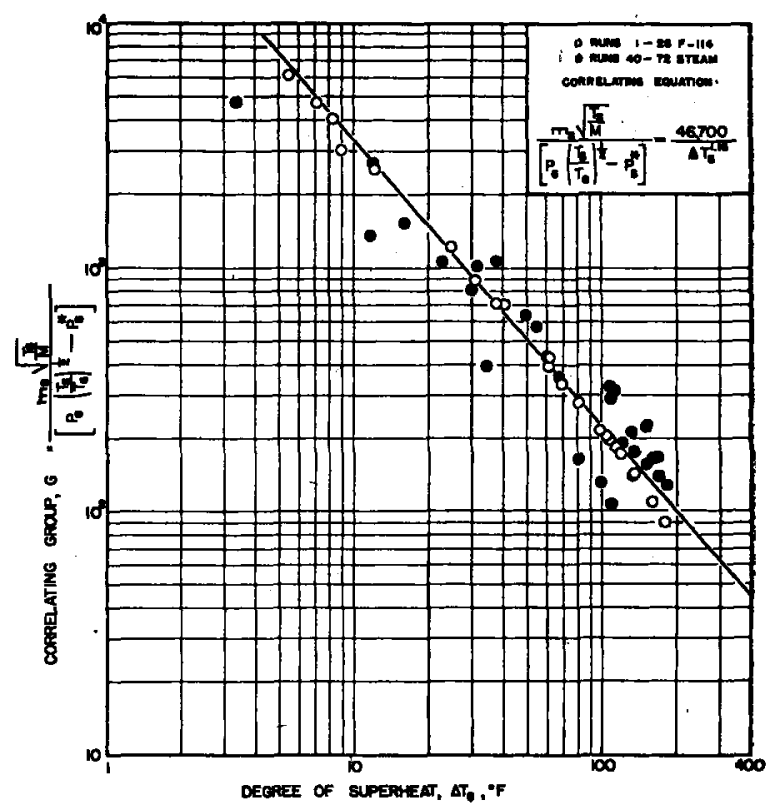

Fig. 9. Correlation of condensing load with superheat as a function of condensation coefficient. 
where $P_{*}^{*}$ and $P_{g}$ are expressed in pounds force) per square inch absolute. The experimental and calculated results are used to calculate $h_{f}$ from Equation (12) and $\phi_{g}$ from Equation (9). These calculations indicate values of $\phi_{0}$ of about 0.007 and justify the use of Equation (8) to eliminate $\Gamma$ in Equation (1). The correlating group defined as

$$
G=\frac{m_{s} \sqrt{\frac{T_{s}}{M}}}{\left[P_{s}\left(\frac{T_{s}}{T_{s}}\right)^{1 / 2}-P_{s}^{*}\right]}
$$

is used for the correlation of the experimental condensing load and the calculated temperature and pressure conditions at the interface with the degree of superheat. The correlating group is plotted against the superheat in Figure 9. Of the two fluids Freon-114 indicates stable film condensation and is expected to give results which agree better with predictions from interphase theory. This is shown by the satisfactory grouping of the Freon-114 results about the line drawn to represent the best trend. It is interesting to note that the present correlation predicts conservative condensing loads for superheated steam condensing by film. The maximum deviation of the results is +12 and $-20 \%$ for Freon-114 and $\pm 50 \%$ for the steam results. The equation of the correlating line in Figure 9 is found to be

$$
\frac{m_{s} \sqrt{\frac{T_{\mathrm{s}}}{M}}}{\left[P_{\mathrm{s}}\left(\frac{T_{\mathrm{s}}}{T_{\mathrm{g}}}\right)^{1 / 2}-P_{s}{ }^{1 / 2}\right]}=\frac{46,700}{\Delta T_{\mathrm{s}}{ }^{1.16}}
$$

Combining Equations (12) and (14) shows the condensation coefficient to be unity at $T_{s}=2^{\circ} \mathrm{F}$. Since the value of $h_{f}$ cannot exceed unity, it may be deduced that for saturated Freon-114 vapor the value of the condensation coefficient is close to unity.

The use of Figure 9 or Equation (14) is recommended for applications involving the film condensation of a superheated vapor outside horizontal tubes. For the given pressure, degree of superheat, and tube-surface temperature, Nusselt's equation and Equation (14) are used to calculate the unknown condensate-surface temperature and the corresponding heat flux and condensing load. The correct value of the condensate surface temperature is that which gives the same calculated heat flux or condensing load from Nusselt's equation and Equation (14).

\section{CONCLUSIONS}

The present investigation reveals some important phenomena encountered during the condensation of superheated vapors.
The effect of superheat in the absence of excessive splashing of the condensate $\cdot$ is a lowering of the heat flux and condensing load and a depression of the condensatesurface temperature below that of the saturated vapor.

The general theory of interphase mass and energy transfer is applicable for the correlation of results obtained with film condensation of superheated vapors. For a thorough understanding of this subject the interfacial temperature and pressure conditions prevailing during the condensation of superheated vapors must be obtained accurately from direct or indirect experimental measurements.

\section{ACKNOWLEDGMENT}

This work was supported by a fellowship provided by the Continental Oil Company.

\section{NOTATION}

$A=$ total outside area, sq. ft.

$g_{c}=$ conversion factor, $4.17 \times 10^{\mathrm{B}}$ (lb. mass) (ft.)/(lb. force) (sq. hr.)

$G \quad=$ correlating group involving $m_{a}, M, T_{a}, T_{g}, P_{s}^{*}$, and $P_{s}$

$h_{c}=$ condensate film coefficient, B.t.u./(hr. ${ }^{\circ} \mathrm{F}$. sq. ft. outside)

$h_{f}=$ condensation coefficient, dimensionless

$h_{i} \quad=$ interfacial film coefficient, B.t.u./(hr. ${ }^{\circ} \mathrm{F}$. sq. ft. outside)

$(-\Delta H)=$ total heat removed, latent heat for saturated vapor, B.t.u./lb.

$m_{0}=$ absolute rate of evaporation, lb./(hr.) (sq. ft.)

$m_{\mathrm{a}} \quad=$ condensing load, lb./(hr.) (sq. ft.)

$M \quad=$ molecular weight, lb. mass/ lb. mole

$P_{0} \quad=$ pressure of gas phase, $\mathrm{lb}$. (force)/sq. ft. abs., lb. (force)/ sq. in. abs. in Equations (12) through (14)

$P_{*}^{*} \quad=$ equilibrium vapor pressure at

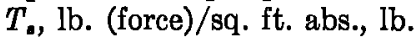
(force)/sq. in. abs. in Equations (12) through (14)

$Q \quad=$ total heat transferred, B.t.u./ hr.

$Q / A=$ heat flux, B.t.u./(hr.)(sq. ft. outside)

$R \quad=$ gas constant, 1,544 (ft.)(lb. force)/(lb. mole) $\left({ }^{\circ} \mathrm{R}.\right)$

$\Delta t_{i} \quad=$ temperature drop through interfacial film $\left(T_{g}-T_{\mathrm{s}}\right),{ }^{\circ} \mathrm{F}$.

$t_{0}$. = outside tube-surface temperature, ${ }^{\circ} \mathbf{F}$.

$t_{w} \quad=$ average tube side water temperature, ${ }^{\circ} \mathrm{F}$.

$T=$ average temperature between $T$, and $T_{a v},{ }^{\circ} \mathrm{R}$.

$T_{o} \quad=$ superheated vapor temperature, ${ }^{\circ} \mathrm{R}$.
T. = condensate surface tempera ture, ${ }^{\circ} \mathrm{R}$. ( ${ }^{\circ} \mathrm{F}$. in Figure 8 )

$T_{\text {ov }}=$ saturation temperature, ${ }^{\circ} \mathrm{R}$ ( ${ }^{\circ} \mathrm{F}$. in Figures 2, 3, and 4)

$\Delta T_{\mathrm{s}} \quad=$ degree of superheat, $\left(T_{g}-T_{\Delta o}\right),{ }^{\circ} \mathrm{F}$.

$u_{g} \quad=$ absolute mean molecular velocity representing rate of mass transfer

$\rho_{L} \quad=$ Liquid density, lb./cu. ft.

$\phi_{\sigma} \quad=\sqrt{\frac{g_{e} M}{2 R T_{\sigma}}} u_{v}$, variable defining $\Gamma$

$\Gamma=$ correction factor, function of error integral

\section{LITERATURE CITED}

1. Alty, T., Proc. Roy. Soc. (London), A131, 554 (1931).

2. - - Phil. Mag., 15, 83 (1933).

3. __, Proc. Roy. Soc. (London), A161, 68 (1937).

4. - and C. A. Mackay, ibid., A149, 104 (1935).

5. Alty, T., and F. H. Nicoll, Can. J. Research, 4, 547 (1931).

6. Balekjian, Garen, Ph.D. thesis, Univ. Mich., Ann Arbor (1956).

7. Bosnjakovic, F., Forsch. Gebiete Ingenieurw., 3, 135 (1932).

8. Claassen, H., Centr. Zukerind., 35, 129 (1927).

9.,- Wärme, 61, 403 (1938).

10. Cornell, David, "Condensation of Superheated Vapors," Heat and Mass Transfer Seminar Report, Univ. Mich., Ann Arbor (1952).

11. Dobkin, G. I., Teplosilovoe Khaz., 1, 21 (1941); see Chem. Abs., 37, 4278.

12. Glbson, L. C., Ph.D. thesis, Univ. Wis. Madison (1952)

13. Jakob, Max, Mech. Eng., 58, 729 (1936).

14. - "Heat Transfer," vol. 1, John Wiley and Sons, New York (1953).

15. Katz, D. L., et al., J. Am. Soc. Refrigerating Engrs., 53, 315 (1947).

16. Kirkbride, C. G., Trans. Am. Inst. Chem. Engrs., 30, 170 (1933-34); Ind. Eng. Chem., 26, 425 (1934).

17. Lang, M., Forsch. Gebiete Ingenieurw., B5, 212 (1934)

18. McAdams, W. H., "Heat Transmission," 2 ed., McGraw-Hill Book Company, Inc., New York (1942).

19. Merkel, F., "Die Grundlagen der Wärmeübertragung, "Steinkopff, Leipzig (1927)

20. Monrad, C. C., and W. L. Badger, Trans. Am. Inst. Chem. Engrs., 24, 84 (1930).

21. Nusselt, W., Z. Ver. deut. Ing., 60, 541, 569 (1916).

22. Prüger, W., Z. Physik, 115, 202 (1940)

23. Rohsenow, W. M., J. H. Webber, and A. T. Ling, Preprint 54-A-145, Am. Soc. Mech. Engrs. (1954).

24. Schrage, R. W., "Interphase Mass Transfer," Columbia Univ. Press, New York (1953).

25. Silver, R. S., Engineering, 161, 505 (1946).

26. Stender, W., Z. Ver. deut. Ing., 69, 905 (1925).

Manuscript received May 9,1957 ; revision received Nov. 18, 1957; paper accepled Dec. $9,1957$. 